\title{
La fortificación del archipiélago filipino en el siglo XVIII. La defensa integral ante lo local y lo global
}

por

Pedro Luengo ${ }^{1}$

Universidad de Sevilla

Este estudio pretende demostrar el interés filipino en crear planes de fortificación complementaria durante el siglo XVIII ante amenazas locales y conflictos globales. Además de las fronteras internas con los igorrotes y los moros, hubo de abordarse el temor a ataques británicos e incluso holandeses. Esta nueva forma de plantear la defensa, teniendo en cuenta varios enclaves complementarios, fue fruto de la cooperación cultural de diferentes tradiciones.

PALABRAS CLAVE: historiografia; ingenieros militares; perspectiva; sangleyes.

Cómo Citar este artículo / Citation: Luengo, Pedro, "La fortificación del archipiélago filipino en el siglo XVIII La defensa integral ante lo local y lo global", Revista de Indias, LXXVII/271 (Madrid, 2017): 727-758. doi:10.3989/revindias.2017.021

Filipinas es el único territorio de las posesiones españolas que cuenta con varias relaciones de plazas durante el siglo XVIII. Esta investigación ha localizado seis de ellas, realizadas entre 1738 y 1759, aún conservadas en archivos internacionales y mayoritariamente inéditas. A partir de su estudio, se pretende demostrar en primer lugar que cada una forma un plan organizado, aunque con carencias, y no suponen una simple yuxtaposición de plantas de fortificaciones. Así, habría que valorar su importancia como antecedentes del Plan Continental de Defensa del ingeniero Agustín Crame (1779). En segundo lugar, se muestra cómo el plan incorporaba a diferentes enclaves afectados por problemas tanto locales - fundamentalmente el envite de los igorrotes en

1 pedroluengo@us.es, ORCID iD: http://orcid.org/0000-0003-0462-4921. 
el norte y los moros en el sur- como internacionales frente a los ataques británicos y en menor medida holandeses. Por último, se pretende demostrar que estos planes, a pesar de ser herramientas de control imperial, no fueron realizados exclusivamente por ingenieros militares. Por el contrario, son fruto del diálogo cultural, frente a la idea de imposición científica por parte del gobierno europeo.

\section{LAS RELACIONES DE PLAZAS: INTENTOS DE PLANES GENERALES DE DEFENSA DE UN TERRITORIO}

\section{Relaciones de plazas, Relaciones geográficas y Atlas de ciudades}

Para apoyar la hipótesis de que las relaciones de plazas se tratan de planes de fortificación es necesario compararlas con otras tipologías similares. Durante la época moderna, cartografiar un territorio en sus diferentes aspectos ha sido una empresa iniciada por muchas naciones, con independencia de su relación con el problema concreto de la expansión europea ${ }^{2}$. En este sentido la reciente historiografía ha incidido en la revisión de las cartografías de las potencias occidentales de territorios asiáticos y americanos, fijándose en aspectos como la etnografía, los sistemas de producción y recaudación o la historiografía, pero en pocos casos desde la perspectiva de la defensa y la ingeniería militar ${ }^{3}$. Así Gruzinski ha planteado las posibilidades que ofrecen dentro de un panorama más amplio de la historiografía hecha en América ${ }^{4}$. También en este sentido, Raj había planteado un análisis de la simbiosis entre tradiciones geográficas en la India británica 5 . Algo similar ha planteado Hostetler para el campo antropológico en China ${ }^{6}$. Todos abordan estas relaciones geográficas de los territorios como una interesante fuente histórica para abordar problemas de transferencia cultural, pero no cuentan con la información de otras fuentes similares como son los atlas de ciudades y las relaciones de plazas.

2 Aunque el problema está planteado por Subrahmanyam, 1997: 761, su contextualización en un ámbito chino queda explicado en Hostetler, 2000: 624.

3 La importancia de estas fuentes queda demostrada por estudios como los de Solano, 1988a. López Guzman, 1997. Pereda y Marías, 2002. Morales, 2003. Para el caso concreto del uso imperial de la cartografía, entre otros estudios, pueden destacarse los de Galland Seguela, 2002.

4 Gruzinski, 2012.

5 Raj, 2004: 73-98.

6 Hostetler, 2000. 
Las relaciones geográficas estaban destinadas a conocer las posibilidades del terreno a partir de una descripción exacta de sus características. Este tipo de documentos comenzaron a realizarse bajo el gobierno de Felipe II, siguiendo las Ordenanzas de Población de $1573^{7}$. En paralelo, y con claras referencias europeas, aparecen los atlas de ciudades, centrados en aspectos urbanos con fines propagandísticos. Por último cabe señalar la existencia de relaciones de plazas, con fines específicamente militares. Así, mientras que las geográficas tenían un carácter más administrativo, los atlas de ciudades se realizaban con fines propagandísticos, y las relaciones de plazas con un fin militar.

Las relaciones geográficas fueron frecuentes en el siglo XVI, pero no tanto en el XVII, cuando se enviaron solo tres cuestionarios generales, en los años 1607,1635 y $1648^{8}$. El encargo a las autoridades indianas no resultaba efectivo, pero la información seguía siendo necesaria. Los atlas de ciudades fueron habituales en Europa durante el siglo XVI y XVII, pero no en los territorios españoles. Mientras Felipe II promocionaba su desarrollo en Europa, en los territorios americanos y asiáticos no se realizaron. Estos títulos carecían de un interés eminentemente defensivo, como puede verse en el Civitates Orbis Terrarum, o el atlas de Anton van Wyngaerde 9 , siendo más cercanas a las representaciones de vedute italianas. Por último, las relaciones de plazas fueron solicitadas por la metrópoli durante todo el siglo XVIII a diferentes enclaves americanos, pero, al parecer, no se realizaron, quizás por confundirse con las relaciones geográficas.

Los planes de defensa diseñados desde la corte requerían de información actualizada no sólo de las fortificaciones sino de otros aspectos como las dotaciones de tropa y de piezas de artillería. Este tipo de datos, muy alejados de los cuestionarios de las relaciones geográficas, muestran un interés diferente, aunque compartan la representación del territorio entre sus herramientas. A pesar de esta información, hasta el momento no parece que fueran eficaces en la articulación de la defensa de los territorios ultramarinos.

7 El Consejo de Indias obtenía información sobre el territorio a través del envío de cuestionarios rellenados por las autoridades indianas (Solano, 1988a). Para valorar las implicaciones arquitectónicas y urbanísticas debe consultarse Morales Folguera, 2001. Más reciente es el trabajo de López Guzmán, 2007.

8 Con la intención de unificar los objetivos, la metrópoli enviaba unos cuestionarios que eran posteriormente completados por las autoridades locales. Con esta información se elaboraban las relaciones que solían formar parte de la correspondencia del gobernador y rara vez fueron publicadas. Las primeras enviadas, de 1604, llegaron de forma tardía y no alcanzaban la calidad requerida desde la metrópoli. Hidalgo Nuchera, 1999: 636.

9 Para las relaciones entre ambos véase Kagan, 1986. 


\section{Relaciones de plazas europeas del siglo XVII en Asia Oriental}

Los conflictos internacionales en los mares asiáticos llevaron a que, durante los siglos XVI y XVII, tanto Holanda como Portugal aumentaran su interés en contar con volúmenes dedicados a informar sobre sus fortalezas ${ }^{10}$. Los primeros solían imprimir copias de mapas con representaciones de las ciudades más importantes, especialmente para el caso asiático. Un caso de esto son las representaciones de Johannes Listing (1656) o del Atlas Vingboons (1666). El caso holandés se convertiría en la imagen de referencia de estos territorios para las copias europeas ${ }^{11}$. Las portuguesas tuvieron un carácter secreto, por lo que serían conocidas en el ámbito ibérico gracias a la unión de las coronas. En un primer momento, Felipe IV pondría en marcha una renovación de esta información. Así se encargaría a António Bocarro la descripción del Estado da Índia ${ }^{12}$, generando un modelo uniforme de descripción de ciudades con un formato diferente al expediente administrativo, donde se incorporaron algunas de las relaciones americanas. Al tratarse de un territorio articulado por enclaves portuarios sin administración del territorio vecino, la defensa es diferente a la que debería plantearse en territorios bajo administración española. Quizás por ello, hasta el momento no se conoce que se encargara un proyecto similar para Filipinas o América en estas fechas, pero resulta evidente que sirvieron de base para las fuentes borbónicas.

Aunque estas imágenes pueden parecer a priori simples representaciones propagandísticas del poder de un imperio, las ibéricas suelen insistir en cuestiones defensivas de gran relevancia. Por ejemplo, el trabajo de Bocarro parece deformar la representación en perspectiva para clarificar la función defensiva de los lienzos murarios. Igualmente se indican las piezas de artillería disponibles en cada lugar, así como los vástagos que asediaban las plazas. En

10 Véase Armas, Duarte de, Livro das fortalezas, sobre las fortalezas portuguesas fronterizas. El original, al parecer, contenía todas las del territorio portugués, Biblioteca Nacional de España, Madrid, ms. 9241.

11 La imagen de Manila, por ejemplo, fue la propuesta por Vingboons como se conserva hoy en la Biblioteca Medicea Laurenziana (Castello 749) o en los Nationaal Archief, VELH0619.69. Morales, 2003: 170-171.

12 Bocarro, António. Livro das plantas de todas as Fortalezas, ciudades e Povoaçoes do Estado da Índia Oriental. Aunque se trata en todos los casos de un manuscrito, existen varias copias con diferentes fechas. La más antigua es la conservada en la Biblioteca Pública de Évora, 1635. COD CXV / 2-1. Según la propia web de la biblioteca existe otro ejemplar en una colección privada. A estas hay que unir la conservada en la Biblioteca Nacional de España (ca. 1635) procedente de la Biblioteca Real, la de la Bibliothèque Nationale de France (ca. 1636), la de la Biblioteca Nacional de Portugal (1639) y un último ejemplar de 1646 conservado en la British Library de Londres. 
cambio, la cartografía holandesa parece centrarse más en la belleza general de la representación y en sus elementos exóticos. Además los casos ibéricos unían a la representación pictórica contenido escrito sobre la situación militar de la plaza, información muy delicada que subraya su carácter secreto. Con todo esto, parece claro que las relaciones de plazas del siglo XVII respondieron a la necesidad de conocer los elementos básicos para la defensa de los enclaves de estos imperios, superando la simple representación estética.

\section{Las relaciones geográficas de Filipinas durante el siglo XVIII}

Filipinas tardó en producir este tipo de relaciones de plazas, pero durante el siglo XVIII envió al menos seis ${ }^{13}$. Es posible que hubiera ediciones anteriores, pero por desgracia, toda esta información almacenada en las bibliotecas reales españolas debió desaparecer durante el incendio del Alcázar de Madrid en la Nochebuena de $1734^{14}$. Esta es, al menos, la razón que da el entonces Intendente General de la Marina, José Patiño Rosales (Milán, 1666-La Granja, 1736), para solicitar a Filipinas descripciones de sus territorios que restituyeran la biblioteca ${ }^{15}$.

El rey quiere tener presente el estado, en que se hayan / los presidios o plazas, que hubiere en todo el distrito de la juris/dicción de esa audiencia, con expresión de sus fortificaciones y for/talezas, respecto de la falta de noticias, que hay de ellas, por el in/cendio acaecido en su Real Palacio en Madrid, con cuyo motivo: ha resuelto su majestad se prevenga a vuestra señoría (como lo hago) re/mita con primera ocasión los planos y relaciones ${ }^{16}$.

13 Sólo los realizados bajo el gobierno de Valdés Tamón han sido tratados someramente en Javellana, 1997, Barrio Muñoz, 2012 o Luengo 2012. El resto permanecían inéditos.

14 Sobre las bibliotecas del Alcázar de Madrid antes del incendio, así como sus colecciones de planos puede consultarse Santiago, 1994: 318-343.

15 Así se explica en la introducción de la Relación en que, de orden de Su Majestad Católica (Dios le Guarde) se declaran las Plazas, Castillo, Fuerzas y Presidios de las Provincias sujetas a su Real Dominio en las Islas Filipinas: Con Delineación de sus Planos y Demonstraciones puntuales de los Pertrechos y Gente de Guerra, Sueldos, Raciones y Municiones para su manutención... Descríbense con noticias, asi esenciales como curiosas, todas estas Provincias, resumiendo lo que rinden para la Real Caja. Y se da razón, con Resumen General de lo Fijo del Haber y Cargas de ella. Formada por el Mariscal de Campo don Fernando Valdés Tamón, a cuyo cargo es el Gobierno de dichas Islas. Año 1739, Biblioteca del Real Palacio (BRP), II/264 y II/279.

${ }^{16}$ La carta de José Patiño, incorporada a la publicación de la Relación de Plazas, tiene fecha de 20 de septiembre de 1735; Valdés Tamón envió recibo de la orden de José Patiño, Archivo General de Indias, Sevilla (AGI), Audiencia de Filipinas (FILIPINAS), 384, n. ${ }^{\circ} 39$. Poco después informa de la necesidad de más tiempo para actualizar la información, AGI, FILIPINAS, 384, n. ${ }^{\circ} 45$. 
Hasta el momento se han podido localizar un total de seis ejemplares con planimetría o vistas de ciudades, cuya datación va desde 1738, año de la primera enviada por el gobernador Valdés Tamón, hasta la toma británica de Manila en $1762^{17}$. Parece razonable que se enviaran todos a la Biblioteca del Palacio Real de Madrid (BPR), pero solo se conservan allí dos de ellos. Además no se tiene noticia de otros ejemplares similares sobre el resto de territorios americanos. De los enviados desde Filipinas solo hubo una impresión cuya tirada debió ser pequeña ya que sólo se conserva un ejemplar en la Biblioteca del Palacio Real. El resto fueron manuscritos, lo que parece indicar el carácter secreto de la información. De todas formas, ninguno de ellos fue enviado como parte de un expediente administrativo.

Antes de la conocida obra de Valdés Tamón, Filipinas había recibido el encargo de remitir a España una relación similar. La copia conservada no incorpora información planimétrica ${ }^{18}$. En ella se facilitaba información sobre Manila y otros enclaves ${ }^{19}$. Resulta significativo que una zona tan importante en este momento como Mindanao no se encuentre entre ellas. En la carta se habla de «mapas» y de «relación». Aunque no hay ningún elemento definitivo, puede pensarse que en el envío se incorporaron también plantas de algunas de estas fortificaciones, en las que recientemente había intervenido el ingeniero militar habanero Juan de Císcara.

\begin{tabular}{|l|c|c|}
\hline \multicolumn{1}{|c|}{ Título } & Año & Signatura \\
\hline $\begin{array}{l}\text { Planos de las plazas, presidios y fortificaciones en } \\
\text { todo el Distrito de las provincias ... en las Islas }\end{array}$ & 1738 & $\mathrm{MN}^{20}, \mathrm{~ms} .1040$ \\
Filipinas & & \\
\hline $\begin{array}{l}\text { Relación en que de orden de su Majestad Católi- } \\
\text { ca... se declaran las plazas, castillos, fuerzas y } \\
\text { presidios de las provincias sujetas a su real domi- }\end{array}$ & $\begin{array}{c}1739 \\
\text { (con } \\
\text { añadidos } \\
\text { de en las Islas Filipinas. }\end{array}$ & BNE, mss. 965 \\
\hline
\end{tabular}

17 Se trata de las cuatro ediciones conservadas de tiempos del gobernador Valdés Tamón, la datada bajo el gobierno del Marqués de Ovando y la que debe pertenecer a tiempos del gobernador Arandía. El interés reciente en estas fuentes comienza con la publicación en inglés de una de las fuentes en 1995. Véase Cuesta e Infante, 1995. Más tarde, la versión manuscrita formó parte de la exposición, Morales, 2003.

18 El encargo había sido realizado a través de despachos con fecha de 18 de julio de 1711 y 6 de julio de 1713. La respuesta no se hizo esperar y fue enviada junto con la carta de 23 de junio de 1716, AGI, FILIPINAS, 133, n. ${ }^{\circ} 21$,

19 Se incluye información de Cavite, Cagayán, Calamianes, Panay, Oton, Cebú, Caraga, Pampanga y Pangasinan.

${ }_{20}$ Museo Naval, Madrid. 


\begin{tabular}{|l|c|l|}
\hline \multicolumn{1}{|c|}{ Título } & Año & \multicolumn{1}{|c|}{ Signatura } \\
\hline $\begin{array}{l}\text { Relación en que [...] se declaran las Plazas [...] } \\
\text { en las Islas Filipinas }\end{array}$ & 1739 & $\mathrm{BPR}, \mathrm{II} / 279^{21}$ \\
\hline $\begin{array}{l}\text { Relación en que [...] se declaran las Plazas [...] } \\
\text { en las Islas Filipinas }\end{array}$ & 1739 & $\mathrm{BPR}, \mathrm{II} / 264$ \\
\hline $\begin{array}{l}\text { Descripción con planos y figuras de la capital de } \\
\text { Manila, puerto de Cavite, fuerzas de los presidios } \\
\text { otras fortificaciones }\end{array}$ & 1753 & $\mathrm{AGI}, \mathrm{MP}, \mathrm{LM}^{22}, 81$. \\
\hline $\begin{array}{l}\text { Descripción de plazas, presidios, y fuertes de las } \\
\text { Filipinas. }\end{array}$ & $1757-1759$ & $\begin{array}{l}\text { LOC } \\
1777 \text { Vault, Phillips } \\
\text { n. }{ }^{\text {o }} \text { 5304. }\end{array}$ \\
\hline
\end{tabular}

La primera versión de estas relaciones de ciudades que no formó parte de un expediente administrativo fue encargada por el gobernador Fernando Valdés Tamón (1729-1739)24. De las diferentes copias enviadas en tiempos de este gobernador, la primera fue manuscrita y se conserva en el Museo Naval de Madrid con fecha de $1738^{25}$. Solo un año más tarde se hicieron dos copias más, una impresa y otra manuscrita, conservadas ambas en la Biblioteca del Palacio Real ${ }^{26}$. Por último cabe citar el ejemplar manuscrito de 1739 conservado en la Biblioteca Nacional de España, publicado en forma de facsímil en $1995^{27}$. Se seleccionaron un total de veintitrés plantas representadas tanto en

21 En algún estudio las signaturas MC/998 y MC/421 han sido considerados dos copias más. Se trata de copias contemporáneas correspondientes a los ejemplares de la institución, y no de ejemplares históricos, por lo que no se incluyen en este estudio.

22 AGI, Sección Mapas y Planos (MP), Subsección de Libros Manuscritos (LM), 81.

23 Library of the Congress, Washington (LOC).

24 Sobre este personaje y el envío de estas obras, entre otras, véase Barrio Muñoz, 2012. Este autor considera que todos estos volúmenes son copias con las lógicas ampliaciones puntuales según eran reenviados.

25 Estos datos fueron dados a conocer por Navarro García, 1989: 542. El ejemplar se titula Planos de las plazas, presidios y fortificaciones en todo el distrito de las provincias que sujeta el real dominio en las Islas Filipinas. Relación de la artillería, tren de su manejo, pertrechos de guerra, tropas regladas de dotación, sueldos, raciones y municiones, con liquidación y separación de su importe al año producto de las rentas y consignaciones de que se reporta según el estado presente, Biblioteca del Museo Naval de Madrid.

${ }^{26}$ La versión impresa fue publicada por Javellana, 1997. La manuscrita fue presentada en el catálogo Morales, 2003: 61.

27 Valdés Tamón, Fernando, Relación en que de orden de su Majestad Católica... se declaran las plazas, castillos, fuerzas y presidios de las provincias sujetas a su real dominio en las Islas Filipinas, Manila, 1739, publicado en Cuesta e Infante, 1995. 
sencilla como en doble página subrayando la importancia de cada enclave (figura 1$)^{28}$.

El sucesor de Fernando Valdés Tamón fue el flamenco Gaspar de la Torre (1739-1745) ${ }^{29}$. Apenas llegado al cargo recibió orden de José de la Quintana para informar sobre la realidad de las islas, lo que debía traducirse en el envío de una nueva relación ${ }^{30}$. Se trata de la versión más completa en lo que a documentación textual se refiere. Quizás esto se explique por su carácter diferente del resto. Aunque comparte con todas ellas el objetivo final, no se trata de una edición manuscrita, sino de un expediente administrativo ${ }^{31}$. No sólo describe puntualmente todos los pueblos del archipiélago, sino que ofrece un detallado informe de los gastos de la corona en las islas así como la documentación acreditativa facilitada por el escribano de la Audiencia ${ }^{32}$. Frente a esta riqueza cabe señalar la falta total de representación gráfica. Aunque en el encargo original se hacía especial hincapié en las fortificaciones y presidios, así como en su estado, el documento prefiere centrarse en la problemática económica y documentar esos gastos ${ }^{33}$. La descripción de ciudades y pueblos ocupa buena parte del legajo, pero con el interés puesto en el número de tributos y en los misioneros que los administraban, siguiendo un modelo mucho más cercano a lo que se enviaba desde América como respuesta a los cuestionarios $^{34}$. Los problemas de fortificación no aparecen de forma indepen-

28 A doble página se representó Manila, Cavite, Playa Honda (actual Zambales), la Fuerza de Santa Isabel de Palawan (Calamianes), la de Iloilo (Otón), la de San Pedro en Cebú, la de Iligan (Cebú), la de Santiago de Dapitan (Cebú), la de San José de Tanda (Caraga), Zamboanga y el plano general de Filipinas basado en el de Murillo Velarde.

${ }_{29}$ Para un estudio de la figura de este flamenco como gobernador de Filipinas véase Rodríguez García, 1976.

30 El expediente generado, conservado en AGI, FILIPINAS, 450, . $^{\circ} 22$ fue citado por Hidalgo Nuchera, 1999: 636. Anteriormente por Serrera Contreras, 1980: 49.

31 Todas las versiones restantes están encuadernadas y cuentan con portada y escudo de armas del monarca reinante. En este caso forma parte de la documentación enviada habitualmente por el gobernador de Filipinas a la metrópoli.

32 El legajo cuenta con 526 folios manuscritos sin documentación gráfica adjunta.

33 «Que remitan así mismo con la mayor/ claridad y distinción posible relaciones de / la consistencia de cada presidio, tanto de los / interiores de esas islas, como de las plazas / marítimas expresando los oficiales de / las planas mayores, ingenieros, y artille/ros las compañías de caballería y infan/tería o batallón y demás dependientes / de que se componen sus respectivas guarni/ciones y los sueldos, que gozan conforme / a sus grados y destinos, y en virtud de qué / reglamentos cédulas y órdenes qué / artillería existe, qué morteros, y de qué calibres / qué armas, qué pertrechos y municiones de / guerra y boca, y sin son correspondientes a / sus dotaciones y si exceden o faltan al/gunos géneros por /el completo de ellos y últi/mamente las fortificaciones de cada presidio / y el estado que tienen», AGI, FILIPINAS, 450, f. 2r.

34 AGI, FILIPINAS, 450, n. $^{\circ} 22$, ff. $56 r-179 v$. 
Figura 1: MaPa de Filipinas con los enclaves Seleccionados EN LAS DIFERENTES RELACIONES DE PLAZAS DEL SIGLO XVIII

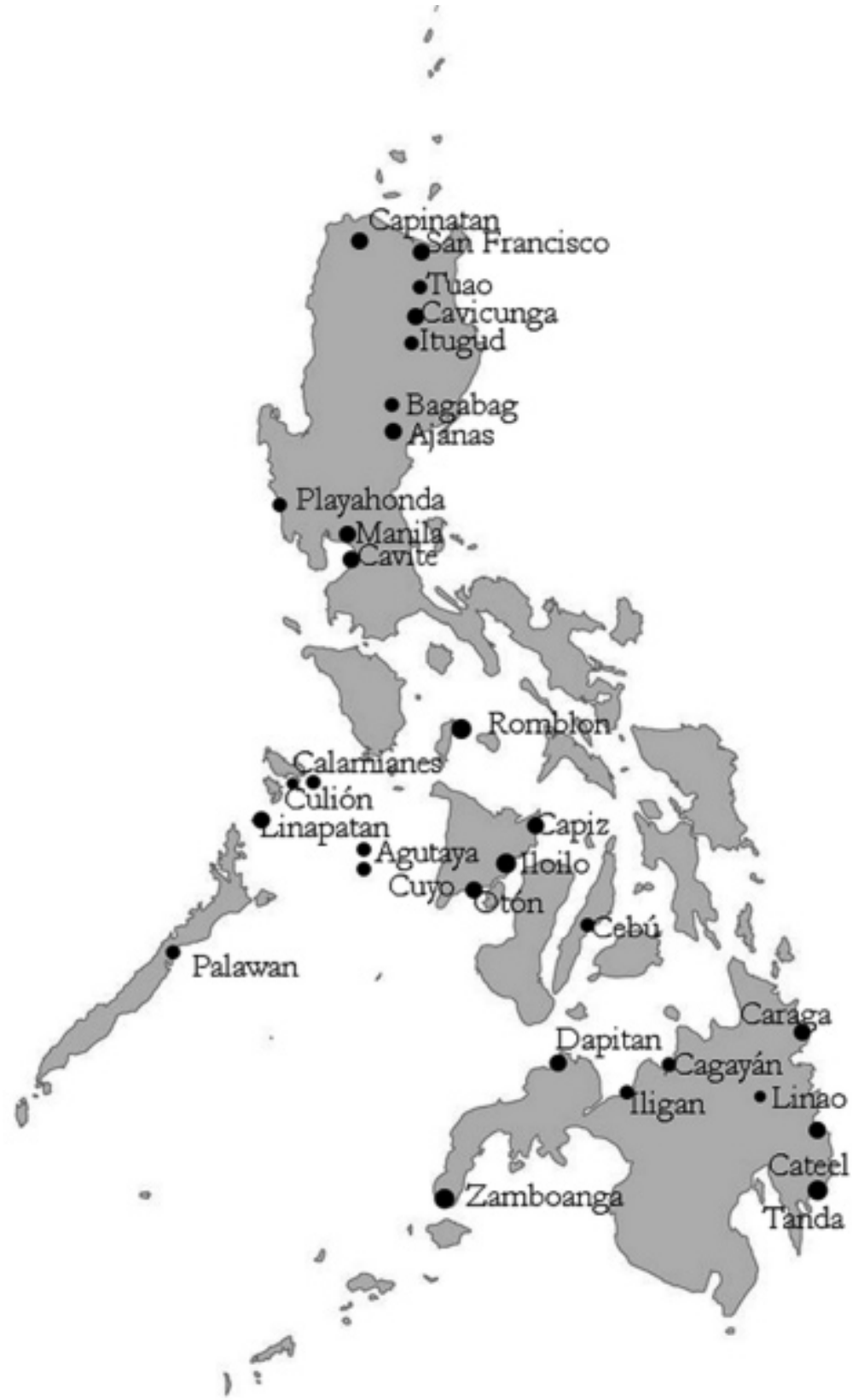


diente, aunque sí existe una relación de la población militar y de los pertrechos defensivos ${ }^{35}$. Aunque tanto el ingeniero como el cabo de obras reales siguieran en activo en Manila, es posible que no se considerara necesario copiar de nuevo todos los planos que habían sido enviados recientemente en las versiones de Valdés Tamón. Además, la escasez de dibujantes que vivía Manila en este momento hacía la empresa aún más complicada.

De estos años es también la Descripción de las Islas Filipinas estudiada por Hidalgo Nuchera ${ }^{36}$. Parece claro que como indica el investigador, esta descripción se beneficia principalmente de la información de las crónicas franciscanas de principios de siglo. Pero la incorporación de datos de índole fiscal y militar, menos habituales en las fuentes religiosas, la acercan a los objetivos tradicionales de las relaciones que se tratan en este trabajo. No parece que se trate de un encargo de ningún gobernador, sino una copia actualizada de la obra del franciscano Juan Francisco de San Antonio ${ }^{37}$. La primera diferencia destacable entre esta obra y la que se vienen comentando es la inexistencia de planos o referencia a ellos. Esta diferencia no es superficial, ya que desde Valdés Tamón las relaciones se utilizaron para indicar las mejoras necesarias en algunas fortificaciones. En estos dos casos solo se informa de la existencia de las mismas. Esta versión se enviaría a la corte durante el gobierno de Filipinas de Juan Arrechederra (1745-1750), entonces arzobispo de Manila. Quizás el perfil del gobernador lo hizo perder interés en el aspecto militar y centrarse en otras cuestiones.

La siguiente versión editada enviada a Europa de la que se tiene noticia debe vincularse con el gobierno de Filipinas por el Marqués de Ovando (17501754), ya que su portada está fechada en $1753^{38}$. De todas formas el encargo a este personaje era muy anterior. Previamente a convertirse en gobernador

35 El mismo documento hace referencia a la orden de José Patiño de 1739, por lo que se conocía el proyecto precedente, pero se prefirió responder con un modelo más americano que el que instituyera Valdés Tamón, AGI, FILIPINAS, 450, n. ${ }^{\circ} 22$, ff. 398r-433v

36 Hidalgo Nuchera, 1999.

37 Crónicas de la apostólica provincia de San Gregorio de religiosos descalzos de Nuestro Santo Padre San Francisco en las Islas Filipinas, China, Japón, etc. Parte primera, en que se incluye la descripción de estas islas, Sampaloc, Nuestra Señora de Loreto, 1738 y 1741.

38 Aunque el ejemplar se encuentra hoy en el Archivo General de Indias, se trata de una adquisición reciente por parte del Ministerio de Cultura. En principio no formó parte de ningún proceso administrativo. Descripción con planos y figuras de la capital de Manila, puerto de Cavite, fuerzas de los presidios y otras fortificaciones en todo el distrito de las provincias que sujeta el real dominio en las Islas Filipinas. Relación de la artillería y su tren, armas y demás pertrechos de guerra, dotación de plazas que tienen, sueldos, raciones y vestuarios que gozan, con inclusión de los sueldos de la Real Capilla, contadurías, colegios y otras oficinas 
de Filipinas, había alcanzado el mando de la Marina $\operatorname{Sur}^{39}$. Desde este puesto, que ostentó desde 1743, desarrolló el encargo de informar sobre los puertos americanos, levantando nuevos planos ${ }^{40}$. Con todo esto, cabe decir que Ovando era un gran conocedor del proyecto de «cartografiar» los territorios hispánicos en toda su extensión cuando llegó a Manila. Quizás por ello, no envió el ejemplar a la metrópoli hasta finalizar su gobierno, por lo que tuvo tiempo para actualizar la información.

La última es más difícil de fechar con certeza. Por un lado, la obra conservada actualmente en Washington incorpora el escudo de armas de Carlos III (1759-1788) ${ }^{41}$. Por otro lado, el resumen de cuentas pertenece a 1757, aunque existen referencias a fechas posteriores a lo largo del volumen ${ }^{42}$. Incluso, en el plano de Manila pueden advertirse edificios como el de la Alcaicería de San Fernando, en obras en 1756, que no aparecía en los planos de las relaciones anteriores (figura 2). Por todo esto, parece probable que se trate de una edición encargada por el gobernador Pedro Manuel de Arandía (1754-1759), quizás enviada por su sucesor Miguel Lino de Ezpeleta (17591761) antes del ataque británico. Otras conclusiones pueden sacarse del propio texto, donde se exponen las dificultades para obtener información sobre el Fuerte de Nuestra Señora de la Concepción del Triunfo de Misamis (hoy Ozamiz City, Misamis Occidental). Los mapas fueron enviados al citado gobernador por los jesuitas según indica el inventario del Colegio de San Ildefonso de Manila, pero parece claro que no llegaron a tiempo ${ }^{43}$. Un último elemento característico es la inclusión de Bagabag (Nueva Vizcaya) en el índice de enclaves (figura 1). La versión enviada por Ovando ya incorporaba la plaza de Ajanas, pero ahora se añade el segundo elemento defensivo contra los igorrotes en la zona. Se trata de una fundación de 1741, pero hasta 1754

que se haya dentro de la ciudad y fuera de ella, de cuyo importe al año se pone sumario y resumen general al final. Año de 1753, AGI, MP, LM, 81.

39 Para un mejor conocimiento del personaje debe citarse el estudio de Ortiz de la Tabla Ducasse, 1974.

40 Se trataba de un proyecto que unificaría los criterios en este tipo de representaciones, mejorando la toma de decisiones desde la metrópoli. Esta empresa estaba además unida al encargo a los virreyes americanos de informar sobre su territorio a partir de la Real Cédula de 2 de diciembre de 1743, AGI, FILIPINAS, 385, n. ${ }^{\circ} 2$.

${ }^{41}$ Descripcion de plazas, prendos, y fuertes de las Filipinas, LOC, G2394-A1D4 1777 Vault, Phillips n. ${ }^{\circ} 5304$.

42 Al describir tanto el Fuerte de San José de Capinatan, como el Fuerte de San José de Cavicunga cita «en este fuerte fueron suprimidas las plazas de su / dotación el año de 1759 por el mariscal de / campo don Pedro Manuel de Arandía gober/nador de estas islas», ff. 40r. y 42 r.

43 Luengo, 2010a: 639. 
Figura 2: MANILA. DESCRIPCIÓN DE PLAZAS, PRESIDIOS, Y FUERTES DE LAS FILIPINAS

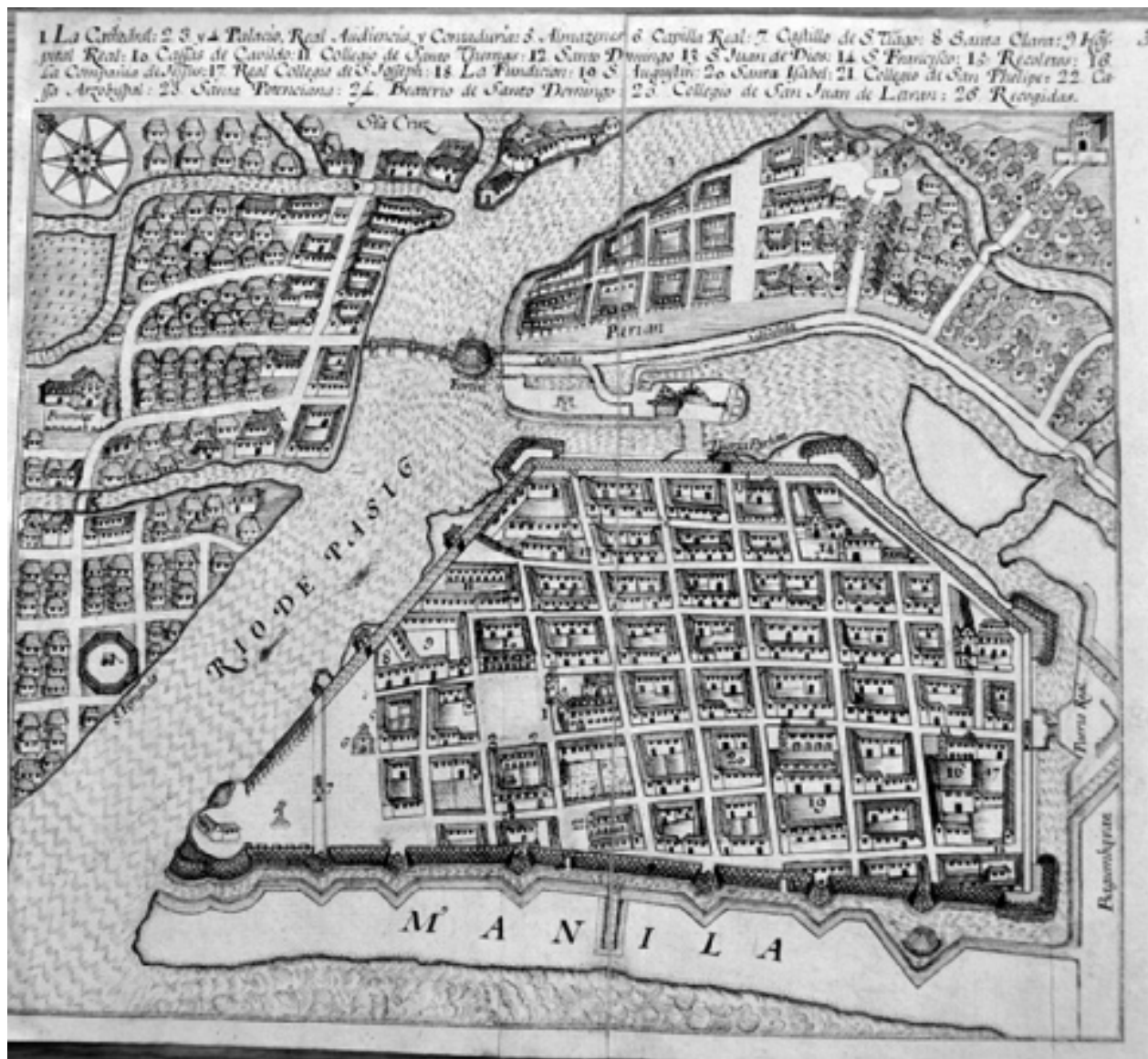

Fuente: Library of the Congress, Washington, G2394-A1D4 1777 Vault, Phillips n. 5304.

su organización y localización no fue definitiva ${ }^{44}$. Por ello, su inclusión apoya la posibilidad de que se trate de una obra tardía dentro del gobierno de Arandía, o su sucesor.

Por desgracia, las versiones promocionadas por los gobernadores Ovando y Arandía cerraron un ciclo. Tras su gobierno se sucedieron períodos cortos y en algunos casos con carácter interino, tales como Miguel Lino de Ezpele-

44 Según Scott el fuerte no sería construido hasta 1752. Scott, 1975: 123. 
ta (1759-1761) o Manuel Antonio Rojo del Río (1761-1762). Posteriormente la toma británica de Manila dentro de la Guerra de los Siete años, modificó definitivamente las relaciones entre la metrópoli y el archipiélago a partir de su devolución ${ }^{45}$. El último tercio del siglo sería el de la llegada de expediciones científicas a las islas, cambiando por completo el concepto de relación geográfica que había sido habitual en las décadas centrales del siglo ${ }^{46}$. Ya no tenía el mismo sentido encargar a las autoridades locales este tipo de información. Ni siquiera la ingeniería militar mantuvo este sistema, enviando a Agustín Crame a realizar un estudio sobre el sistema defensivo, excluyendo a Filipinas y al sur de América ${ }^{47}$. Las nuevas ideas ilustradas llegadas con Carlos IV unificaron los criterios dentro de los territorios hispánicos, pero redujeron la participación de profesionales como los sangleyes que venían incorporándose a estas tareas.

Parece que esta solicitud a Filipinas no se hizo extensiva a otros territorios, que continuaron enviando las tradicionales relaciones geográficas ${ }^{48}$. No obstante, es posible que la solicitud llegara a muchos puntos de América, pero que cada uno realizara una interpretación de los contenidos que debían incorporar. Si a esto se le suma el tiempo que muchos gobernadores necesitaron para recopilar toda la información, habría que tener en cuenta las relaciones recibidas en la corte durante las décadas centrales del siglo XVIII. En este sentido, habría que considerar el intento del rey de reactivar la recopilación de datos al enviar a los virreyes americanos una Real Cédula solicitando más información sobre sus territorios, lo que se tradujo en algunas relaciones geográficas como las realizadas en México ${ }^{49}$. De forma similar Quito, Chile, Guatemala y otros territorios irían enviando la información en forma de relaciones hasta bien entrada la segunda mitad del siglo ${ }^{50}$. Todas ellas carecen de la información sobre elementos defensivo de las de Filipinas, a lo que habría

45 Sobre la defensa de Manila en el ataque británico véase Luengo, 2017.

46 Este tema, y sus componentes artísticos y arquitectónicos, ha sido largamente estudiado. Sotos Serrano, 1982. Bañas Llanos, 1992: 85-108. Bernabeu Albert, 1992. Luengo, 2012: 171-192.

47 Calderón Quijano, 1953. Canellas Anoz, 2012: 227-246.

48 Parece que la Descripción general... de todas las ciudades de España (1736), aunque dedicada a José Patiño no forma parte de esta discusión. El texto no incluye documentación gráfica, ni trata la problemática defensiva. Se centra en valorar las comunicaciones entre diferentes territorios. Alonso de Arce, Blas Alonso, Descripción general para escribir a todas las ciudades de España, villas y lugares más remotos de ella, reinos y potencias extranjeras..., Madrid, Antonio Sanz, 1736.

49 Real Cédula de 19 de julio de 1741, AGI, MP, México, 141, 142, 144, 146 y 152.

50 Solano, 1988b; 1995. Ponce Leiva, 1991. Luján Muñoz, 2006. 
que añadir la falta generalizada de planimetría, mucho más si es referida a ciudades concretas ${ }^{51}$. No cabe duda de que Filipinas era una frontera delicada del imperio, pero no eran menores los problemas de seguridad en el ámbito antillano de donde no se conocen este tipo de requerimientos ${ }^{52}$.

Una vez identificadas las relaciones conservadas, cabe indicar que todas ellas proponen una selección de enclaves de todo el archipiélago, aportando información planimétrica de sus fortificaciones y datos sobre los efectivos de defensa. Su carácter bélico no está apoyado por un plan de defensa integral específico, lo que le resta funcionalidad. A pesar de esto, es evidente que la selección de fuertes responde a la identificación previa de amenazas, tanto internas como externas. Además, puede valorarse como una respuesta a las políticas de centralización planteadas por los borbones en el ámbito de la defensa, e incluso entenderse dentro de las propuestas del recién creado Cuerpo de Ingenieros bajo la tutela de Jorge Próspero de Verboom.

\section{RELACIONES GEOGRÁFICAS DE FILIPINAS: UNA PROPUESTA LOCAL PARA UN PROBLEMA GLOBAL}

Para consolidar la hipótesis de que estas relaciones proponen un sistema de fortificación en conjunto, y no una simple yuxtaposición de vistas de ciudades, es necesario observar cómo responden tanto a problemas de defensa interna como internacionales. Para ello es necesario observar los conflictos más destacados de la época y valorar si se abordaban de forma conjunta entre diferentes fortificaciones (figura 1). Además es necesario saber si se han obviado fortificaciones importantes, de las que se tendría información, pero que carecían de sentido ante estos peligros.

\section{Las fronteras internas: Moros e Igorrotes}

La presencia española en Filipinas debía proteger cuatro flancos principales, en forma de fronteras interiores tanto marítimas como terrestres, y fronteras externas. En primer lugar cabe señalar el sector sur. Estos conflictos están relacionados por un lado con los moros de Maguindanao y con el as-

51 Sobre los intereses concretos de las mexicanas y venezolanas del siglo XVIII puede consultarse Hidalgo Pérez, 2005: 215-234.

52 Diferentes estudios recientes vienen subrayando la importancia de las fortificaciones en Asia, no solo como elemento defensivo, sino especialmente como base para la creación de una imagen de fuerza con gran impacto sobre los circuitos económicos. Chaudhuri, 1978: 111. 
censo de los holandeses en la zona a principios del siglo XVIII 53 , y por otro con el creciente poder del Sultanato de Joló, apoyado más tarde por intereses británicos encabezados por Dalrymple ${ }^{54}$. En la década de los treinta tanto Tay-Tay como Zamboanga, fueron asediadas y atacadas, respondiendo las tropas hispanas con ataques sobre ciudades enemigas. Aquí hay que incorporar también los incidentes con el apresamiento del buque holandés Langerak en Mindanao en 173355. Aunque en 1737 el citado Valdés Tamón había firmado la paz con el sultán, a mediados de siglo los ataques arreciaron hasta llegar a las provincias de Cebú, Albay o Batangas. En esta época, la población de las Visayas se vio notablemente diezmada por los continuos ataques. Los ataques serían rápidos y carentes del nivel de desarrollo de la artillería y métodos de asedio ya habituales en Europa. Por ello, las fortificaciones bastionadas debían ser suficientes, a pesar de suponer un anacronismo frente a un posible ataque de una potencia occidental.

La selección de enclaves incluía plazas importantes como Zamboanga o Dapitan en el Mar de Joló ${ }^{56}$. Pero también era necesario proteger los puertos del norte de Mindanao ante los ataques desde el interior, para garantizar la conexión con Bohol o Cebú, para lo que estaban los fuertes de Iligan y Cagayán. La isla mantenía además protegido su sector sur con el fuerte de Tubig y la zona este con el de Tandag (Surigao del Sur) y Cateel (Davao Oriental) ${ }^{57}$. Aún más interés ofrece el fuerte de Lanao — citado como Linao-. Se encuentra en el interior de la isla, en la orilla del lago del mismo nombre y fue establecido para impedir las internadas de los «moros» por el río hacia la costa.

En segundo lugar, cabe delimitar el sector suroeste, dominado navalmente por el Sultanato de Joló y en menor medida por los propios holandeses ${ }^{58}$. Se trataba de una zona especialmente frágil ante ataques navales rápidos, como solían realizar los joloanos. Por ello, las riberas del Mar de Joló supusieron un importante interés para el sistema defensivo, a pesar de que la posibilidad de un ataque holandés fue fundamentalmente un temor recurrente

53 Laarhoven, 1989: 177-181.

54 Warren, 1985: 17-37.

55 Ibidem: 295-332.

56 Zamboanga ha sido históricamente una de las fortalezas más importantes para garantizar la defensa del archipiélago. Los problemas durante el gobierno de Valdés Tamón no fueron menores como ha mostrado Barrio Muñoz, 2012: 66-74.

57 Tubug debía servir de cierto control de los navíos de la Compañía Neerlandesa de las Indias Orientales (VOC), en las aguas de Mindanao, ya que el lugar de encuentro de esta flota era la Isla de Sarangani, en el extremo sur de la Isla de Mindanao.

58 Mallari, 1989: 41-66. 
fruto de los conflictos de siglos anteriores. Servían además de control de los navíos que viajaban normalmente entre Malaca y Macao, o incluso entre Batavia y Japón ${ }^{59}$. Entre los enclaves de este sector cabe destacar Cebú, pero también los de Palawan, atacados en numerosas ocasiones entre 1730 y $1734^{60}$. A estas hay que añadir los de la zona norte del Mar de Joló, con Cuyo o Agutaya e incluso los del sur, como Zamboanga, pasando por los de Iloilo o Iligan.

El tercer foco conflictivo del momento se ubicaba en la zona norte de la Isla de Luzón ${ }^{61}$. Esta zona fue especialmente convulsa durante la primera mitad del siglo XVIII ${ }^{62}$. Las dificultades de adoctrinamiento de los igorrotes llevaron a continuas reyertas tanto en el sector oriental como en el occidental de la isla. La década de los treinta supuso un especial aumento en las tensiones. Así, en las fuentes históricas se hace referencia a un número alto de fuertes en materiales pobres, aunque también a murallas de piedra. La mayoría de estos enclaves no aparecen citados en las relaciones de plazas, lo que demuestra una importante descoordinación entre las tropas allí destacadas y los compiladores de estas relaciones. Pero la laguna es aún mayor en el sector occidental, del que no se destaca ni un solo caso, a pesar de los conflictos conocidos $^{63}$. La ciudad de Lal-lo, en el sector oriental, mantuvo un papel fundamental en estos conflictos, aunque la dispersión de la población entre áreas montañosas hacía difícil la protección del territorio con grandes fortificaciones. Era mucho más práctico contar con un sistema de pequeños fuertes que protegieran principalmente el cauce del río y diferentes enclaves.

Estas tres zonas debían defenderse de ataques terrestres y navales, pero casi siempre de ejércitos con técnicas rudimentarias de asedio. Por tanto el sistema de defensa debía adaptarse, lo que no debe interpretarse siempre como un arcaísmo técnico. En las fortificaciones de estos ejemplos abundan los perímetros defensivos, ya sean en piedra o madera, con algunos baluartes de plantas diferentes. El diseño no está previsto para soportar el ataque de baterías de artillería o navíos de guerra, sino para defenderse de ataques numerosos como debían hacer los igorrotes o los moros. El problema era similar en

59 Los contactos comerciales entre Dejima (actual Nagasaki) y Batavia (actual Yakarta) se mantuvieron desde el siglo XVI hasta el XIX, incluso durante el cierre del país nipón al comercio con Occidente. Tras un siglo XVII especialmente enriquecedor, el siglo XVIII vivió un lento languidecimiento de las relaciones comerciales que llevaron a simplificar los contactos a dos flotas al año.

60 Barrio Muñoz, 2012: 59-66 y 74-85.

61 Keesing, 1962: 259.

62 Scott, 1977: 84-138.

63 Ibidem: 106-138. 
la zona sur, la suroeste y la norte. Por tanto, no es extraño que los modelos utilizados sean similares. De hecho incluso los materiales parecen haber sido los mismos, a pesar de las variaciones habituales por zonas geográficas.

\section{Los conflictos internacionales}

La cuarta zona de especial interés defensivo era Manila y otras ciudades aledañas como Cavite y Playa Honda. Los ingenieros destinados a la capital mostraron siempre temor a posibles ataques de potencias europeas, no valorándose la posibilidad de alzamientos locales. Desde el asalto de Anson al Galeón durante la Guerra de la Oreja de Jenkins (1743) hasta la toma de Manila durante la Guerra de los Siete Años (1762), el archipiélago temía un ataque europeo, especialmente británico ${ }^{64}$. Esto obligó a invertir en mejorar las fortificaciones de estos enclaves, especialmente los dos primeros, aunque los trabajos fueron siempre lentos. A diferencia de lo que ocurre en el resto de fortificaciones del archipiélago, con excepción de Zamboanga, aquí el perfil abaluartado está proyectado para soportar artillería contemporánea. Se adoptan soluciones que difícilmente contrarrestan un alzamiento numeroso en tropas con poca formación militar, como podría ser un ataque local. En cambio estudian cómo reducir el impacto de una ofensiva que siga los procedimientos europeos. También a diferencia de los anteriores, los ingenieros militares planificaron planes de defensa que tenían en cuenta tanto Cavite como Manila, aunque siempre valorando como posibilidad un ataque europeo.

\section{La defensa integral del territorio}

Con los datos anteriores se puede observar que las relaciones de plaza fueron enviadas a la península como muestra de la capacidad del archipiélago de afrontar sus retos defensivos. La comparación entre diferentes fuentes, con varias dataciones, permite valorar los cambios en este «teatro bélico», con inclusión de nuevos enclaves en las sucesivas ediciones. Todas las plazas representadas por Valdés Tamón son repetidas en Ovando con excepción de Itugut, Tuao y Paragua, añadiendo solo la de Ajanas (actualmente Aritao, Nueva Vizcaya), Bagabag y Calamianes. Las dos primeras corresponden con el problema de los igorrotes en el Valle de Cagayán ${ }^{65}$. La tercera, formaba parte del conflicto joloano, que venía en aumento con los intereses británicos.

\footnotetext{
64 Luengo, 2012: 165-245; 2017.

65 Scott, 1970: 705.
} 
Parece un refuerzo más a las ya habituales de Culión y Linacapán en la zona norte del Mar de Joló.

Hasta el momento resulta difícil considerar cualquiera de estos ejemplos como sistemas defensivos concebidos siguiendo el modelo francés. De hecho no se cuenta con planes de defensa conjuntos, de los que ni siquiera se conservan para el binomio Cavite-Manila. Las fortificaciones son tratadas de forma individual y no se vinculan en ningún momento. Frente a esta visión, cabe indicar que la fortificación española de América no funcionó tradicionalmente con sistemas defensivos que incluyeran varios puntos. Por ejemplo, el Caribe o el Golfo de México se protegieron a través de ciudades concretas, y no por sistemas de pequeñas fortificaciones dispersas. Así, islas como Cuba, Santo Domingo o Puerto Rico tardaron en fortificar su perímetro, o ni siquiera llegaron a hacerlo. Por tanto, Filipinas propone una fórmula de defensa inédita en el ámbito hispanoamericano hasta ese momento.

Otra idea que apoya la posibilidad de que se trate de una propuesta parecida a un sistema defensivo es el hecho de que estas relaciones estaban mostrando un problema común entre todas ellas, marginando otras fortificaciones de las que se tenía información y contaban con gran importancia en la defensa general del archipiélago. Una muestra destacable es la inexistencia de noticias sobre algunas de las fortificaciones de la parte oriental. Desde el fuerte de Cateel (Mindanao) hasta el norte de Luzón no se representa ninguna fortificación, aunque debían existir. Por ejemplo, se sabe que tanto Tanauan y Palo (Leyte) como Guiuan (Samar) contaban con una pequeña fortificación desde antiguo ${ }^{66}$. Aún más sorprendente es el hecho de que el Estrecho de San Bernardino, por donde dejaba el archipiélago el Galeón de Manila camino de Acapulco, nunca estuviera fortificado ${ }^{67}$. En la misma línea, la zona noroeste del archipiélago tampoco aparece defendida, con excepción de Playa Honda (actual Zambales). Incluso ciudades como Vigan, puerto y capital de Nueva Segovia, no aparece citada en la relación ${ }^{68}$. Otros enclaves fortificados del

66 Tanauan, Palo y Guiuan fueron enclaves administrados por la Compañía de Jesús, fortificándose el primero desde 1704, el segundo desde 1718 y el tercero desde 1754. Javellana, 1997: XXI.

67 Según Javellana la fortificación de muchos de estos enclaves se debe a finales del siglo XVIII, pero la de otros como el de Mobo (Masbate) y Patacale (Camarines) son anteriores, de 1752 y 1756 respectivamente. Ninguno aparece en las ediciones de mediados de siglo. Javellana, 1997: XX.

68 Javellana pudo identificar diferentes formas de fortificaciones previas a estas ediciones en casos como la iglesia de Paoay (Ilocos Norte), Cagayancillo (Islas Cagayán) o Atimonan (Quezon). Los faros de Ilocos Sur no han podido datarse por el momento. Javellana, 1997: XVII-XIX. 
ámbito oriental de Luzón, conocidos por los conflictos con los igorrotes, tampoco se incorporan. Con todo esto, puede llegarse a la conclusión de que la obra de Valdés Tamón ofrece destacada información sobre la defensa del archipiélago, pero no se trata de una visión completa. La consolidación de este esquema llevó a que en el futuro apenas se alterara, lo que subraya la carencia de información sobre algunas zonas.

A partir de lo anteriormente expuesto se puede concluir que las relaciones de plazas no pretenden ofrecer una visión general de las fortificaciones existentes, sino sólo de las amenazadas. Así, pretende servir de base para concebir un posible sistema, no mostrar un conjunto establecido previamente. $\mathrm{Su}$ finalidad era plenamente defensiva, y no exclusivamente fortificadora, ya que tenía en cuenta otros aspectos como la tropa o los pertrechos. Por tanto es lógico que no se enviaran directamente al Cuerpo de Ingenieros, sino que su gestión correspondiera a los capitanes generales de las islas, cargo que solía ostentar el gobernador. Su finalidad es estrictamente militar, sin las implicaciones propagandísticas de los atlas de ciudades o las cuestiones administrativas de las relaciones geográficas. Pero una tarea tan delicada y técnicamente tan compleja debía realizarse con calidad contrastada ante el receptor final, la metrópoli, de ahí la importancia de conocer sus autores.

\section{DiÁLOGO CULTURAL E INGENIERÍA MILITAR}

\section{Problemas de autoría}

La amplitud geográfica del conjunto de fortificaciones seleccionado requeriría de un gran equipo de profesionales que lo documentara y actualizara. Para entender mejor su desarrollo, y especialmente su trascendencia, es necesario abordar el problema de sus posibles autores, así como las dificultades de representación evidentes en los dibujos. La escasa población española, especialmente en el ámbito artístico y especialmente del dibujo, debió obligar a contar con el trabajo de artistas orientales y misioneros, además de los ingenieros destacados en Manila. Según parece, en todos los casos se realizaron con cierta precipitación. Una vez recibida la orden en Manila se intentó remitir la información en el siguiente Galeón ${ }^{69}$. En un año resultaba difícil ac-

69 Las prisas obligaron en el caso de Valdés Tamón a realizar una segunda versión. También hubo premura en el caso de Gaspar de la Torre. Sólo el Marqués de Ovando tardó varios años en decidir remitir la obra definitiva. El caso de Arandía, con un volumen sin fechar, resulta difícil de analizar. 
tualizar todos los datos recogidos durante el trabajo in situ de un ingeniero militar. Algunos documentos apuntan a que tanto los datos como los planos eran solicitados desde Manila y posteriormente unificados bajo un único patrón ${ }^{70}$. Este hecho multiplica el número real de los autores originales, especialmente de los dibujos. En su realización habría que unir a los ingenieros militares, muchos misioneros que estuvieron encargados de fortificaciones concretas, como fue el caso de los agustinos recoletos en Palawan.

Una vez recopilados los planos en Manila, el ingeniero militar al cargo se encargaría de unificarlo en un modelo común. El número de ingenieros destinados a Manila no subió de uno hasta la segunda mitad del siglo ${ }^{71}$. Esto obligaba a dejar desatendidas las obras de fortificación, entre otros proyectos, si el ingeniero partía para documentar el estado de las poblaciones del resto de islas ${ }^{72}$. Por ello, cabe pensar que fueron los colaboradores de los ingenieros, normalmente nativos, los que realizaron gran parte de este trabajo ${ }^{73}$. Su formación fue siempre muy limitada, a diferencia de otros casos de los territorios hispanos, y en Filipinas no llegaron a puestos de relevancia durante el siglo XVIII ${ }^{74}$. Esto llevó a que los sistemas de representación orientales y occidentales confluyeran en procesos de diálogo cultural, produciendo obras de gran interés.

Antes de analizar estos equipos de trabajo, es necesario intentar identificar los autores finales de las obras en la capital. Debido a la escasez de personal especializado en Manila en estos años, la autoría de los planos puede vincularse bien con el mestizo Tomás de Castro, bien con algunos de sus colaboradores más inmediatos, tales como Ignacio Fernández Valenzuela, entonces cabo superintendente de obras reales ${ }^{75}$. Incluso las portadas de los manuscri-

70 Este sistema se conoce para los jesuitas que administraron el sur del archipiélago, y puede extrapolarse a los agustinos recoletos que construyeron y administraron muchas de las fortificaciones de Palawan. Aguilera y González Tascón, 1985: 213-224.

71 Luengo, 2013.

72 Recientes estudios han demostrado la escasa movilidad de los ingenieros militares en América, una vez llegados a un destino concreto, incluso cuando el aumento de efectivos de época borbónica se empezó a notar en ultramar. Luengo, 2014.

73 Díaz-Trechuelo Spínola, 1959.

74 A nivel general hay que destacar como Silvestre Abarca, un ingeniero nacido en La Habana, llegó a ser la máxima referencia en el ramo durante la segunda mitad del siglo XVIII. Era un momento aún temprano en la incorporación de americanos y asiáticos al Cuerpo de Ingenieros. Como muestra Galland solo un 1,5\% procedía de América en 1777, dato que ascendió al 2,3\% en 1790. Galland Seguela, 2002: 211.

75 Por desgracia, el archivo de los planos de Tomás de Castro debió ser sustraído durante la toma de Manila por los británicos en 1762, ya que fueron publicados posteriormente en Inglaterra. Luengo, 2012. 
tos, tanto la de 1738 como la de 1739, podrían ser del primero, quien era conocido por sus dotes como pintor de miniaturas, aunque no se conserva ninguna $^{76}$. Para mediados del siglo XVIII, estos profesionales seguían en Manila con importantes problemas de salud, pero son conocidas sus desavenencias con los gobernadores de este momento, en especial con Arandía ${ }^{77}$. La llegada del Marqués de Ovando habría supuesto un cambio radical en el panorama arquitectónico de Manila. Coincidía además con el inicio de las obras de la catedral, la incorporación del peruano Esteban de Rojas Melo y la llegada del italiano Juan de Uguccioni. Todo ello había marginado a la generación previa, entre ellos Castro y Fernández Valenzuela, y había impulsado la formación de sangleyes bajo el magisterio de Uguccioni. La posterior llegada a Manila de Lucas de Jesús María, quien sería nombrado cabo superintendente de reales obras por Arandía en detrimento de Fernández Valenzuela, debió mantener este contexto ${ }^{78}$.

Una última posibilidad a tener en cuenta es que este tipo de dibujos fueran producidos por la escuela de grabadores filipinos, formada en primer lugar por el franciscano polaco Valcio y continuada después por Nicolás de la Cruz Bagay (1701-1771) y otros seguidores ${ }^{79}$. Ellos fueron los que produjeron muchas de las grandes obras impresas en la ciudad, con ejemplos como el Mapa de Filipinas de Murillo Velarde (1734), también ligado con la figura de Valdés Tamón. En contra de esta opción existen varias cuestiones. En primer lugar, tanto Cruz Bagay como Vicente Laureano Atlas u otros, tuvieron costumbre de firmar sus obras ${ }^{80}$. En segundo lugar, el uso de la perspectiva cónica puede encontrarse en sus trabajos. Aunque el resultado no es totalmente satisfactorio es evidente que la conocían ${ }^{81}$. Además, aunque se prefiere la perspectiva paralela, no se utilizan soluciones con puntos de vista múltiples, como sí son habituales en estas relaciones. Decantarse por una opción con-

76 Díaz-Trechuelo Spínola, 1959: 75.

77 El gobernador Arandía tilda de «dos inútiles» a los citados Castro y Fernández. Carta de Arandía. 1 de septiembre de 1756, AGI, FILIPINAS, 920. Citado en Luengo, 2012: 239.

78 Las desavenencias entre Arandía y estos ingenieros llevaron a que un misionero recién llegado se incorporara a un puesto militar. Además de las dificultades que ofrecía el puesto para ejercerse con idoneidad, la oferta requería de la aprobación por parte de la orden agustina descalza en la metrópoli. Luengo, 2012: 226-232.

79 Díaz-Trechuelo Spínola, 1962: 277-306. Más reciente son los trabajos de Luengo, 2010b: 437-445. O bien Luengo, 2010c: 223-241.

80 En los casos de varios dibujos es normal encontrar uno firmado y el resto no. En ninguna de las versiones conocidas se ha podido encontrar firma alguna.

81 Un caso claro de esto es el Túmulo levantado en Manila durante las exequias de la reina María Amalia, grabado por Cruz Bagay en 1762, AGI, MP, FILIPINAS, 45. 
creta resulta difícil con estos datos. Resulta probable que el autor final se limitara a copiar las fuentes diversas recopiladas.

\section{Figura 3: Vista de la Fuerza de Romblón (Panay) en las ediciones DE ValdÉs Tamón, Ovando y ARandía}
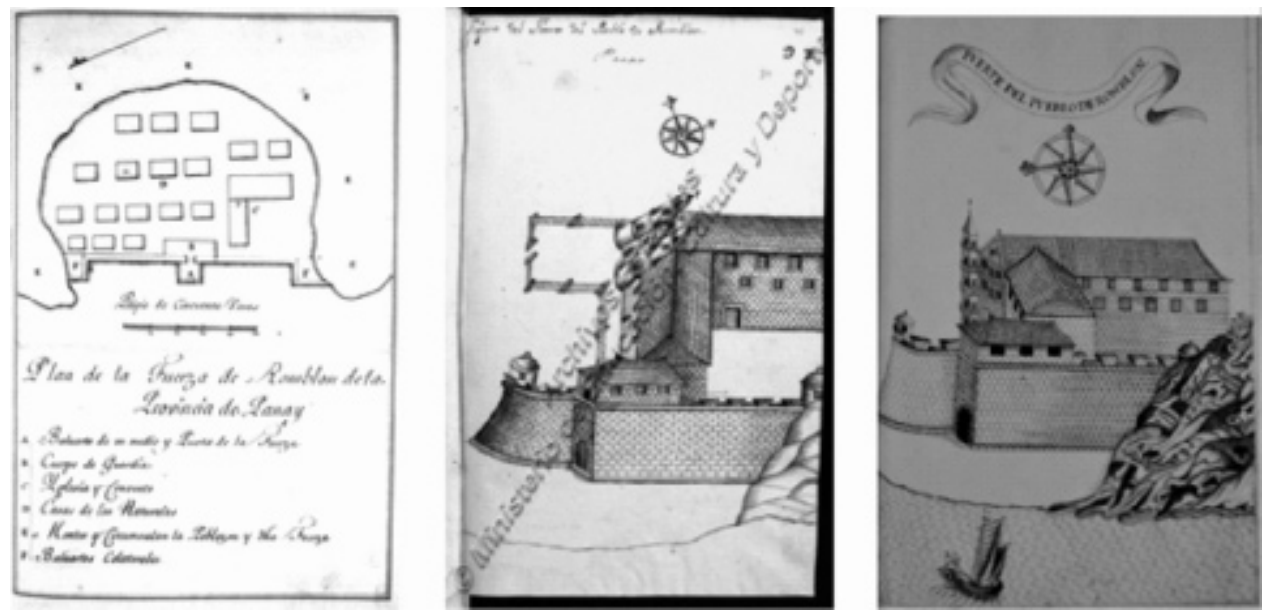

A pesar de la diferencia de fecha entre la obra de Ovando y la de Arandía, el parecido entre ambas versiones es muy notable (figura 3). En primer lugar, cabe destacar que la realización de las vistas es similar en ambos volúmenes. Se comparten problemas de representación o soluciones con respecto a la perspectiva. Por el contrario no puede decirse que exista una copia literal de todas las representaciones. En resumen podría interpretarse que son dos versiones a partir de las mismas fuentes, más que una copia actualizada. Siendo la de Washington de mayor calidad, especialmente en cuestiones de perspectiva, la comparación de las vistas de Manila en ambos ejemplares demuestra una clara relación entre ambas. La información aséptica del ingeniero Castro, contrasta con esta nueva interpretación de la ciudad a la que se ve abocado el artista de mediados de siglo.

\section{Problemas de representación espacial y transferencia cultural}

Además de los autores finales de las relaciones, las fuentes utilizadas para realizarlos en Manila debieron ser muy variadas, mostrando procesos de trans- 
ferencia cultural de gran interés. En las primeras versiones se ofrecen todas las vistas con planimetría, en lo que parece un archivo de un ingeniero militar. En cambio a mediados de siglo se decide cambiar la forma de representación, lo que obligaba a cartografiar de nuevo todos los enclaves con el tiempo que eso conllevaba. El responsable de tal modificación, el Marqués de Ovando, no era simplemente un gobernador, sino que unía a su experiencia cartográfica previa ciertos conocimientos de fortificación ${ }^{82}$. Probablemente quería subrayar la importancia de una visión mucho más estereográfica por encima de la simple planimetría. Los alzados de edificios militares, religiosos y civiles tomaban un protagonismo junto con el entorno geográfico que hasta ese momento apenas habían tenido.

Esta propuesta, más visual que la planimetría, no debe confundirse con la función estética de los citados atlas de ciudades. La renuncia a la planta como fórmula de representación frente a vistas aéreas, resulta más ilustrativa para el análisis militar, pero requiere de una mayor capacidad técnica del dibujante. Se opta por una representación más visual que exacta. Todo ello exige al autor de la fuente original un buen conocimiento de las técnicas de representación en perspectiva, lo cual no fue común ni en China ni en Manila ${ }^{83}$. Aunque los frailes subrayaran la capacidad de generar trampantojos por parte de los pintores chinos en las obras efímeras de las fiestas de Manila, lo cierto es que no se conservan ejemplos. Parece lógico pensar que las dificultades que se encontrarían los jesuitas a la hora de enseñar perspectiva lineal en una escuela pictórica como la corte de Pekín serían extrapolables al ámbito manilense ${ }^{84}$. Esto viene apoyado por las representaciones de estas relaciones de mediados de siglo. Los tipos de perspectivas utilizados son la isonométrica y una variante de la caballera, obviándose la perspectiva cónica. Precisamente eran éstas las que no se conocían en China. Por otro lado los dibujos utilizan múltiples puntos de vista, lo que deforma el resultado final a los ojos occidentales. Esta técnica era habitual en oriente, aunque ni siquiera los planos de Pekín realizados por los jesuitas en este momento las mantuvieron.

Un ejemplo para comprender fácilmente esta diferencia lo ofrecen las representaciones de fuertes que aparecen en estas relaciones. Fundamentalmente son dos sistemas diferentes los utilizados. Por un lado el que conjuga la planta con vistas frontales de los alzados de las murallas (figuras 5 y 6 ).

\footnotetext{
82 Luengo, 2012: 198-202.

83 Como ha mostrado recientemente Chen, la presencia de un pintor novohispano en el sur de China se convirtió en una atracción para la población local por su capacidad de pintar en perspectiva. Chen, 2009: 116.

84 Corsi, 2004.
} 
Figura 4: FuerTe De ZAMBOANGA

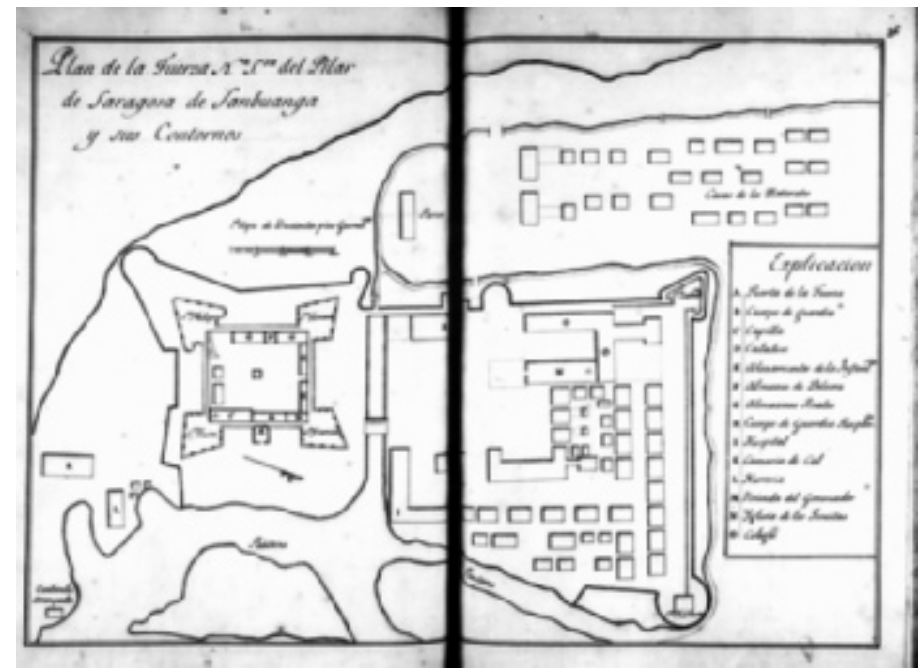

Fuente: BPR, II/264, f. 36.

Figura 5: Fuerza de Zamboanga. DesCripCión de PLAZAS, PRESIDIOS, $Y$ FUERTES DE LAS FILIPINAS

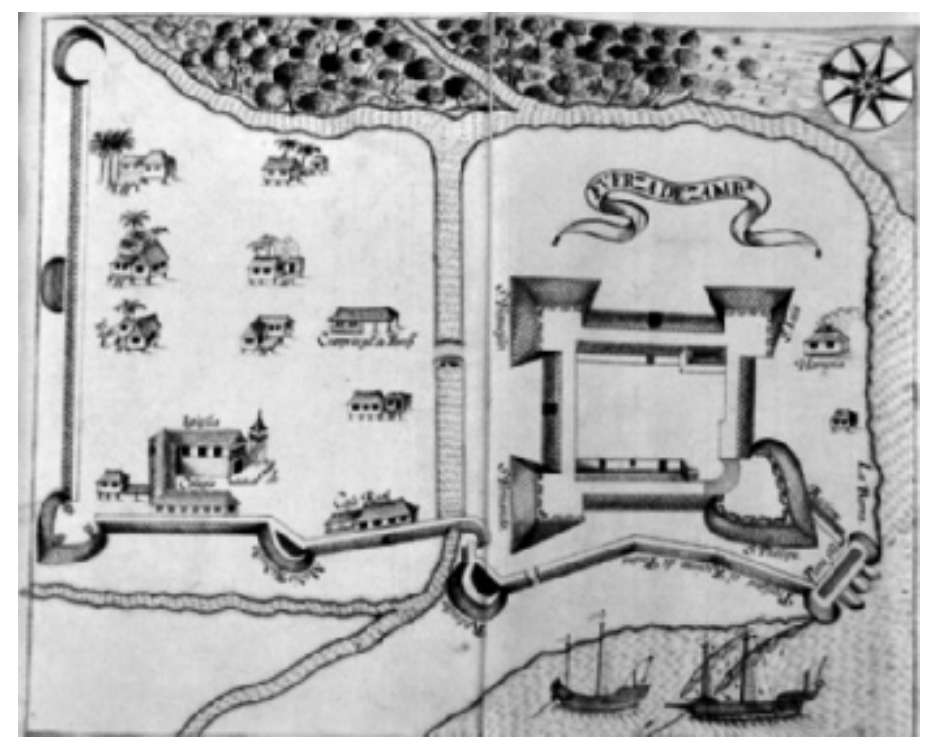

Fuente: LOC, G2394-A1D4 1777 Vault, Phillips n. ${ }^{\circ} 5304$. 


\section{Figura 6: Fuertes de Cuyo y Playa Honda. DescripCión de plazas, PRESIDIOS, Y FUERTES DE LAS FILIPINAS}
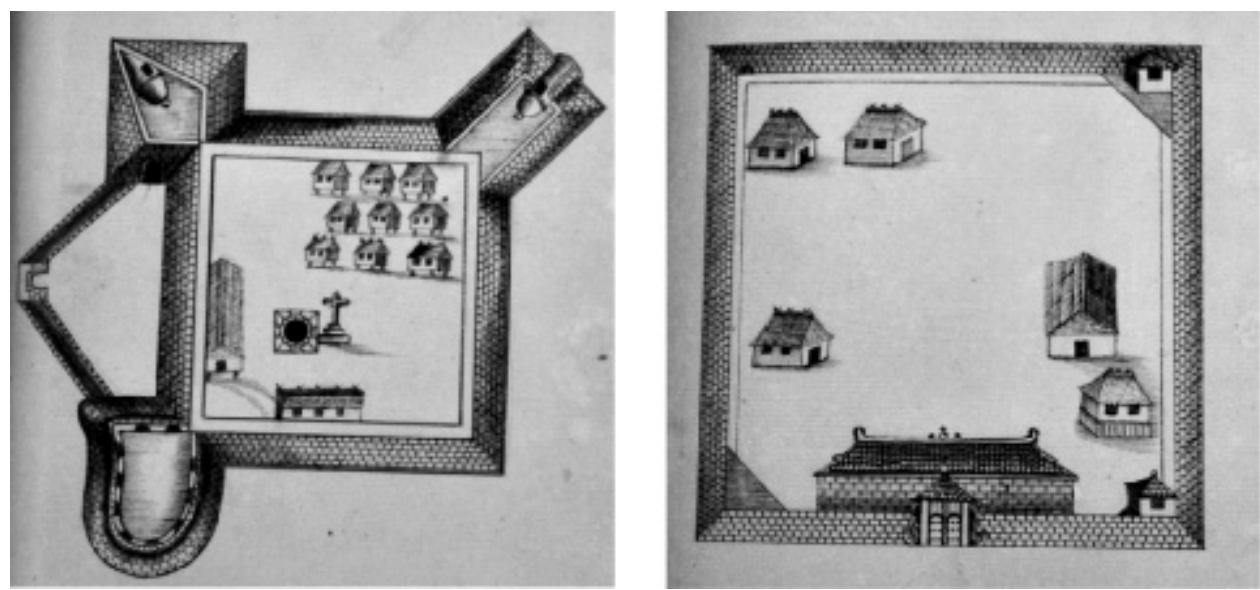

Fuente: LOC, G2394-A1D4 1777 Vault, Phillips n. ${ }^{\circ} 5304$.

Esta solución renuncia a los sistemas de perspectiva mencionados, pero permite valorar los problemas defensivos de la planta junto con la información de los alzados. En occidente no se utiliza, mientras que los mapas de ciudades chinas del siglo XVII la usan constantemente ${ }^{85}$. El resultado debía ser muy poco atractivo para los europeos, que difícilmente podían enjuiciar la calidad de la fortificación a partir de esos datos. La metrópoli, y más concretamente el Cuerpo de Ingenieros, prefirió siempre la representación en plantas y alzados, material que se exigía al ingeniero militar destacado en Manila. Un segundo sistema de representación fue la vista de pájaro (figuras 2 y 3 ). En este caso se utiliza una perspectiva paralela. Como método resulta muy eficaz en aquellos fuertes de planta cuadrada, al elevar el punto de vista con respecto al plano. Más difícil resulta afrontar una representación mucho más baja. Las murallas del primer plano parecen convivir entre una visión frontal y la representación en perspectiva. Está claro que la vista se realiza sin definir previamente el punto de fuga, lo que genera múltiples indecisiones.

El problema de la representación en perspectiva parecía quedar aminorado frente a la capacidad evocadora de las nuevas representaciones (figuras 3, o

85 Aunque los ejemplos son numerosos pueden citarse los mapas de Huoqing zhou, en la Prefectura de Lijiang en la provincia de Yunan, Wellcome Library, Londres, Asian Collection, Chinese ms., 103. También puede citarse el mapa de la provincia de Canton conservado en la Biblioteca Nacional de Francia, Département Cartes et plans, GE AA-658. 
5 y 6). Esta decisión de sustituir la visión en planta por otra a vista de pájaro obligó a prescindir de las escalas, aunque no de la orientación mediante la presencia de la rosa de los vientos ${ }^{86}$. Las relaciones dejaban de ser útiles para «medir el imperio», labor habitual de los ingenieros de la corona, y se convertían en «ilustraciones» de territorios mal conocidos y más difíciles de defender ${ }^{87}$. Esto lleva a pensar que la aceptación de los sistemas occidentales de medición seguía sin ser total en oriente ${ }^{88}$. Resultaban un punto intermedio del citado diálogo cultural, pero esto restaba eficacia científica, necesaria en la corte europea. Con estas ilustraciones era imposible hacer mediciones sobre la capacidad de tiro, el tamaño de las fortificaciones, su capacidad o sobre las ventajas de la propia orografía, por citar algunos ejemplos. Este problema de transferencia cultural hacía inútil la representación como elemento de análisis de la capacidad defensiva del enclave. Tal hecho resulta aún más destacable en un momento como este, en el que la llegada de arquitectos como Juan de Uguccioni, el citado Ovando o poco más tarde Lucas de Jesús María habría permitido adoptar las convenciones de representación establecidas por el Cuerpo de Ingenieros ${ }^{89}$.

El probable intento de Ovando de contar con un apoyo visual que abarcara más elementos de juicio que la simple planta de Valdés Tamón, le llevó a ofrecer soluciones más cercanas a las vistas de ciudades que a las visiones estereográficas de los ingenieros europeos. Así, las relaciones empezaron a detenerse en detalles anecdóticos como la arquitectura local (figuras 2, 5 y 6). En la mayoría de estos dibujos la arquitectura europea resulta menos interesante que la vernácula. Así se diferencian entre el caserío varios patrones

86 Este elemento lleva a pensar que la obra no fue realizada por un ingeniero militar, ya que tenían orden de enviar la planimetría con varias escalas, lo que tampoco se cumplía estrictamente. Véase la Ordenanza de 1718 en Capel, Sánchez y Moncada, 1988: 34-38. La rosa de los vientos es en la mayoría de los casos confusa.

87 En la portada del Milicia y descripción de las Indias (Madrid, 1599) el capitán Bernardo de Vargas Machuca adoptó el lema «A la espada y el compás, más y más y más y más». En él se representaba al capitán con un compás con forma de espada en la mano midiendo el globo terráqueo. Este instrumento era propio de cartógrafos e ingenieros militares, como se observa en el retrato de otro tratado contemporáneo Rojas, Cristóbal de, Teoría y práctica de la Fortificación, Madrid, Luis Sánchez, 1598.

88 El problema de la implantación de los sistemas españoles de medida espacial en Filipinas es aún difícil de valorar, aunque como afirma Woods, puede equipararse a lo que sucedió con los sistemas cronológicos. Woods, 2001: 235-250. Un trabajo anterior donde se trata el problema de los sistemas de medición aplicados a arquitectura es el de Zialcita, 2006: 17.

89 Durante las clases de las diferentes academias de ingeniería se explicaban las «reglas del arte y de convenio» donde se especificaban aspectos como la aplicación de los colores o el modo de determinar las sombras. Capel, Sánchez y Moncada, 1988: 212. 
tanto tipológicos como en el uso de los materiales, aunque no se pueda identificar cada uno de ellos con una zona concreta del archipiélago. Por ejemplo, existen construcciones sobre pilotes, tanto de una planta como de dos alturas, con plantas rectangulares o con forma de L. Entre los materiales, las cubiertas son de nipa, siendo excepcional el uso de la teja, pero los muros parecen representados tanto con tabla, como con caña e incluso parece poderse interpretar que se hicieron de mampostería. La sillería es exclusiva de los elementos defensivos y de la arquitectura religiosa. Por desgracia, por el momento resulta difícil identificar las tipologías planteadas por Alarcon para la arquitectura prehispánica en estas representaciones ${ }^{90}$. Parece claro que con todo este despliegue de detalles la intención de los dibujos era mostrar las particularidades locales con respecto al resto de territorios hispanos, en línea con lo que hacían los atlas de ciudades. Aunque los materiales utilizados en las construcciones civiles era una información necesaria en cualquier plan de defensa, parece claro que estas relaciones iban subrayando el carácter visual sobre el analítico. De un compendio informativo para la toma de decisiones globales se pasó a un elenco de vistas de ciudades con un interés más artístico que militar.

\section{CONCLUSiOnes}

Como resultado de los análisis ofrecidos pueden plantearse algunas conclusiones. En primer lugar, parece claro que las relaciones de plazas de Filipinas no fueron una empresa de un único gobernador, sino una práctica habitual al menos entre 1738 y 1761. Sus antecedentes no se encuentran en modelos propios del ámbito hispanoamericano, sino de la presencia europea en los mares asiáticos. En cuanto a su finalidad, se ha mostrado que no se trata de una simple representación artística o con fines administrativos de las plazas, sino que sólo se explican desde una perspectiva defensiva, que poco a poco iría modificándose hacia un carácter más visual. Dicho esto, ninguna de las relaciones muestra un programa sistematizado de protección ante diferentes ataques. Se trata de recopilaciones de materiales diversos por un único profesional, probablemente el ingeniero militar al cargo. A pesar de esto, los datos habían sido tomados por profesionales locales o misioneros destinados en cada zona. Por tanto, suponen una fuente útil para valorar los problemas de transferencia cultural en aspectos como la representación tridimensional o incluso las técnicas constructivas.

\footnotetext{
90 Alarcon, 2003: 21-68. Zialcita, 2005: 283-294.
} 
A partir de la toma británica la protección de los territorios se modificó considerablemente. La apertura de los puertos españoles al comercio internacional, así como los primeros intentos de conexión del archipiélago con Europa a través del Cabo de Buena Esperanza, restaron interés a algunos territorios del archipiélago. El Cuerpo de Ingenieros modificaría poco a poco su estructura interna, cediendo gran protagonismo a los ingenieros jefe de cada plaza y posteriormente a las comandancias.

Por último, cabe indicar que los resultados alcanzados en este estudio podrían tener un traslado al ámbito de la puesta en valor del patrimonio, conservado o no. Por desgracia, la mayoría de los enclaves citados han modificado sustancialmente su aspecto. A pesar de esto, este estudio saca a la luz procesos de diálogo cultural entre tradiciones diversas, propuesta muy alejada de la imposición imperialista que se ofrece aún en algunos materiales divulgativos. Partiendo de esta última línea, los futuros estudios deberían continuar comparando este tipo de diálogos interculturales con los conocidos en otras zonas geográficas, ya sean del continente asiático, o del americano, o bien de otros marcos cronológicos. Esto permitirá en el futuro agrupar los procesos de interacción cultural por grado de profundidad y resultados.

\section{BIBLIOGRAFÍA}

Aguilera, Concepción y González Tascón, Ignacio, "Las islas Filipinas", Puertos y Fortificaciones en América y Filipinas, Madrid, CEHOPU, 1985.

Alarcon, Norma I., Philippine Architecture. During the pre-Spanish and Spanish periods, Manila, UST Publishing House, 2003. Primera edición de 1998.

Bañas Llanos, Belén, "Expediciones científicas españolas al Pacífico, en la segunda mitad del siglo XVIII", Revista española del Pacifico, 2/2 (Madrid, 1992): 85-108.

Barrio Muñoz, José Ángel del, Vientos de reforma ilustrada en Filipinas. El gobernador Fernando Valdés Tamón (1729-1739), Sevilla, CSIC, 2012.

Bernabeu Albert, Salvador, El Pacífico ilustrado: del lago español a las grandes expediciones, Madrid, Fundación MAPFRE, 1992.

Calderón Quijano, José Antonio, Historia de las fortificaciones en Nueva España, Sevilla, Escuela de Estudios Hispano-Americanos, 1953.

Canellas Anoz, Magdalena, "El Archivo General de Indias", Alicia Cámara Muñoz, Los Ingenieros Militares de la Monarquía Hispánica en los siglos XVII y XVIII, Madrid, Ministerio de Defensa, 2006. 
Capel, Horacio, Sánchez, Joan Eugeni y Moncada, Omar, De Palas a Minerva. La formación científica y la estructura institucional de los ingenieros militares en el siglo XVIII, Barcelona/Madrid, Serbal/CSIC, 1988.

Chaudhuri, K. N., The Trading World of Asia and the English East India Company, 1660-1760, Cambridge, Cambridge University Press, 1978.

Chen, Hui-Hung, "Chinese Perception of European Perspective: a Jesuit Case in the Seventeenth Century”, The Seventeenth Century, 24/1 (Durham, 2009): 97-128.

Corsi, Elisabetta, La fábrica de las ilusiones: los jesuitas y la difusión de la perspectiva lineal en China (1698-1766), México, El Colegio de México, Centro de Estudios de Asia y África, 2004.

Cuesta, Mariano e Infante, Violeta, "Prólogo", Report in which, by order of his catholic majestic... the strongholds, castles, forts and garrisons of the provinces under his royal dominion in the Philippine Islands are listed, Madrid, Turner, 1995.

Díaz-Trechuelo Spínola, M. ${ }^{a}$ Lourdes, Arquitectura española en Filipinas. 15611898, Sevilla, Escuela de Estudios Hispanoamericanos, 1959.

Díaz-Trechuelo Spínola, M. a Lourdes, "Grabadores filipinos del siglo XVIII", Anuario de Estudios Americanos, XIX (Sevilla, 1962): 277-306.

Elliott, John H., España, Europa y el mundo de ultramar. 1500-1800, Madrid, Taurus, 2009.

Galland Seguela, Martine, "Los ingenieros militares españoles en el siglo XVIII", John Brian Harley, The New Nature of Maps. Essays in the History of Cartography, Baltimore, Johns Hopkins University Press, 2002.

Gruzinski, Serge, "Les voies de l'américanisation: espace américain et écriture de l'histoire au XVIe siècle", s-Spania. Revue interdisciplinaire d'études hispaniques médiévales et modernes, 14 (Paris, 2012).

Gutiérrez, Ramón, "Ingenieros militares en Sudamérica. Siglo XVIII", Revista Castillos de España. IV Congreso de Castellología, (Madrid, 2012): 227-246.

Hidalgo Nuchera, Patricio, "Una corografía ilustrada inédita: la Descripción de las Yslas Philipinas de la Real Academia de la Historia de Madrid", Anuario de Estudios Hispanoamericanos, 56/2 (Sevilla, 1999): 627-650.

Hidalgo Pérez, Eloísa, "El contenido de las Relaciones Geográficas mexicanas y venezolanas: Cambios e influjos ilustrados", Antonio Gutiérrez Escudero y María Luisa Laviana Cuetos (coords.), Estudios sobre América: siglos XVI-XX, Sevilla, Asociación de Estudios Americanos, 2005: 215-234.

Hostetler, Laura, "Qing Connections to the Early Modern World: Ethnography and Cartography in Eighteenth-Century China", Modern Asian Studies, 34/3 (Cambridge, 2000): 623-662. 
Javellana, René B., Fortress of Empire. Spanish Colonial Fortifications of the Philippines. 1565-1898, Makati, Bookmark, Inc., 1997.

Kagan, Richard (dir.), Ciudades del Siglo de Oro. Las vistas españolas de Antón Van den Wyngaerde, Madrid, Viso, 1986.

Keesing, Felix M., The Ethnohistory of Northern Luzon, Standford, Standford Univeristy Press, 1962.

Laarhoven, Ruurdje, The Maguindanao Sultanate in the 17th Century. Triumph of Moro Diplomacy, Quezon City, New Day Publishers, 1989.

López Guzmán, Rafael, Territorio, poblamiento y arquitectura. México en las Relaciones Geográficas de Felipe II, Granada, Editorial Universidad de Granada/Atrio Editorial, 2007.

Luengo, Pedro, "Noticias sobre el Colegio de San Ildefonso de Manila y el desarro1 lo de las artes en Filipinas durante el siglo XVIII", Artigrama, 25 (Zaragoza, 2010a): 631-644.

Luengo, Pedro, "Fray Marcin Placyd Albrecht Wałczak. El comienzo del grabado en Filipinas", La cultura del barroco español e iberoamericano y su contexto europeo, Varsovia, Universidad de Varsovia, 2010b: 437-445.

Luengo, Pedro, "Z Polski do Manilii. Brat Marcin Placyd Albrecht z Wałcza (16221728)", Studia Franciszkańskie, 20 (Cracovia, 2010c): 223-241.

Luengo, Pedro, Intramuros: Arquitectura en Manila, 1739-1762, Madrid, Fundación Universitaria Española, 2012.

Luengo, Pedro, Manila, plaza fuerte. Ingenieros militares entre Europa, América y Asia, Madrid, CSIC-Ministerio de Defensa, 2013.

Luengo, Pedro, "Movilidad de los ingenieros militares en Cuba a finales del siglo XVIII", Quiroga, 6 (Granada, 2014): 36-47.

Luengo, Pedro, "Military Engineering in Eighteenth-Century Havana and Manila: The Experience of the Seven Years War", War in History, 24/1 (Londres, 2017): 4-27.

Luján Muñoz, Jorge (ed.), Relaciones geográficas e históricas del siglo XVIII del Reino de Guatemala, Guatemala, Universidad del Valle de Guatemala, 2006.

Mallari, Francisco, "Camarines towns: defenses against moro pirates", Quaterly of Culture and Society, 17 (Cebu, 1989): 41-66.

Morales, Alfredo J. (coord.), Filipinas. Puerta de Oriente. De Legazpi a Malaspina, Madrid, SEACEX, 2003.

Morales Folguera, José Miguel, La construcción de la utopía: el proyecto de Felipe II (1556-1598) para Hispanoamérica, Madrid, Biblioteca Nueva, 2001. 
Navarro García, Luis, Historia general de España y América: los primeros Borbones. América en el siglo XVIII, vol. 11, Madrid, RIALP, 1989.

Ortiz de la Tabla Ducasse, Javier, El Marqués de Ovando, gobernador de Filipinas, 1750-1754, Sevilla, Escuela de Estudios Hispanoamericanos, 1974.

Pereda, F. y Marías, Fernando (ed.), El Atlas del Rey Planeta. La "Descripción de España y de las costas y puertos de sus reinos" de Pedro Texeira (1634), Hondarribia, Nerea, 2002.

Ponce Leiva, Pilar, Relaciones histórico-geográficas de la Audiencia de Quito: siglos XVI-XIX, Madrid, CSIC, 1991.

Raj, Kapil, "Connexions, croisements, circulations. Le détour de la cartographie britannique par l'Inde, XVIIIe-XIXe siècles", Bénédicte Zimmermann y Michael Werner (dirs.), De la comparaison à l'histoire croisée, Paris, Seuil, 2004: 73-98.

Rodríguez García, Vicente, El gobierno de Don Gaspar Antonio de la Torre y Ayala en las Islas Filipinas, Granada, Universidad de Granada, 1976.

Santiago, Elena, "Las bibliotecas del Alcázar en tiempos de los Austrias", Fernando Checa (coord.), El Real Alcázar de Madrid: dos siglos de arquitectura y coleccionismo en la corte de los reyes de España, Madrid, Nerea, 1994: 318-343.

Scott, William Henry, "Igorot Responses to Spanish Aims: 1576-1896", Philippine Studies, 18/4 (Manila, 1970): 695-717.

Scott, William Henry, History on the Cordillera: Collected Writings on Mountain Province History, Baguio City, Baguio Printing \& Publishing Company, 1975

Scott, William Henry, The Discovery of the Igorots. Spanish Contacts with the Pagans of Northern Luzon, Quezon City, New Day Publishers, 1977 (primera edición en 1974).

Serrera Contreras, Ramón M. a "'Estudio preliminar", Suplemento al Theatro Americano. La ciudad de México en 1755, México, UNAM, 1980.

Solano, Francisco de, Cuestionarios para la formación de las Relaciones Geográficas de Indias. Siglos XVI-XIX, Madrid, CSIC, 1988a.

Solano, Francisco de, Relaciones geográficas del Arzobispado de México, 1743, Madrid, CSIC, 1988b.

Solano, Francisco de, Relaciones geográficas del Reino de Chile: 1756, Madrid, CSIC, 1995.

Sotos Serrano, Carmen, Los pintores de la expedición de Alejandro Malaspina, Madrid, Real Academia de la Historia, 1982.

Subrahmanyam, Sanjay, "Connected Histories: Notes towards a Reconfiguration of Early Modern Eurasia", Modern Asian Studies, 31/3 Special Issue: The Eurasian Context of the Early Modern History of Mainland South East Asia, 1400-1800 (Cambridge, Jul. 1997): 735-762. 
Warren, James Francis, The Sulu Zone. 1768-1898. The Dynamics of External Trade, Slavers, and Ethnicity in the Transformation of a Southeast Asian Maritime State, Quezon City, New Day Publishers, 1985.

Woods, Damon L., "Measuring Space and Time in seventeenth-century Philippines", M. ${ }^{a}$ Dolores Elizalde, Josep M. Fradera, y Luis Alonso, (eds.), Imperios y naciones en el Pacífico. Colonialismo e Identidad Nacional en Filipinas y Micronesia, vol. II, Madrid, CSIC, 2001: 235-250.

Zialcita, Fernando N., Authentic though not exotic. Essays on Filipino Identity, Quezon city, Ateneo de Manila University Press, 2005.

Zialcita, Fernando N., Philippine Ancestral Houses.1810-1910, Quezon City, GCF Books, 2006. Primera edición en 1980.

Fecha de recepción: 3 de enero de 2015.

Fecha de aceptación: 26 de mayo de 2015.

\section{The fortification of the Philippine archipelago in the eighteenth century. Integral defense in the face of local and global conflict}

This study aims to demonstrate the Philippine interest in creating additional fortification plans during the eighteenth century in the face of both local and global conflicts. In addition to dealing with the Igorot and Moros in the interior, they had to address the threat of British and also Dutch attacks. This new approach to defense, allowing for various additional settlements, was the result of cross-cultural cooperation from a variety of traditions.

KEY WORDS: historiography; military engineer; perspective technique; Sangleys. 